\title{
Prevalence of postpartum anal incontinence: a cross sectional study in Northern Sri Lanka
}

\author{
N Rajeshkannan ${ }^{1}$, A Pathmeswaran ${ }^{2}$ \\ (Index words: postpartum faecal incontinence, episiotomy, Sri Lanka)
}

\begin{abstract}
Objectives To estimate the prevalence of postpartum anal incontinence (Al) and to highlight associated factors that account for variation in the prevalence in Vavuniya district in Northern Sri Lanka.

Methods A community based cross sectional study was conducted. Sample included all mothers (hospital and home deliveries) who had completed postpartum period between 1st August and 30th September 2007. Participants were identified from the "expected date of delivery" registers maintained by public health midwives. Data were collected by trained public health midwives at the respondents' houses using an interviewer administered questionnaire.
\end{abstract}

Results The mean age of the 540 postpartum mothers interviewed was 28 years (range: 16 - 44). Majority $78 \%$ $(n=423)$ were Sri Lankan Tamils, 13\% $(n=68)$ Sinhalese and remaining $9 \%(n=49)$ Moors. Thirty nine percent $(n=209)$ were primi parous, $81 \%(n=435)$ had a normal vaginal delivery and $79 \%(n=344)$ had an episiotomy. Out of 540 mothers, $16.5 \%$ (95\% Cl: 13.4 - 19.6) reported anal incontinence. Among them only $39.3 \%(n=35)$ had consulted a health worker for the symptom. In the bivariate analysis the following factors were significantly associated with anal incontinence: parity, history of an episiotomy, duration of labour $>12 \mathrm{hrs}$, mode of delivery (vaginal), family income and maternal age (teenage). But the multiple logistic regression analysis revealed only the episiotomy status as an independent risk factor (adjusted odd ratio: 3.4 (95\% Cl: 1.28 - 8.9).

Conclusions Anal incontinence is not an uncommon symptom in postpartum mothers and majority of affected individuals avoided seeking medical attention. Factors associated with increased risk of anal sphincter damage should be considered during delivery and an attempt should be made to reduce it.

Ceylon Medical Journal 2013; 58: 76-79

\section{Introduction}

Anal incontinence (AI) is regarded as an "unvoiced symptom” and affected individuals avoid seeking medical attention [1]. Faecal incontinence is also a distressing condition, recognised for its negative impact on quality of life for women of all ages. Although estimates vary widely depending on the study population and the definition of faecal incontinence, population-based studies suggest that its prevalence in community dwelling adults is $2 \%$ to $12 \%[2,3]$. A major cause of faecal incontinence in young healthy women is anal sphincter tear during vaginal child birth [4]. The incidence of clinically detected obstetric sphincter tears is $3 \%-24 \%[5,6]$. These injuries are usually repaired surgically at the time of delivery. Recent studies have reported sub-optimal outcome in about $50 \%$ of these women, leading to various degrees of anal incontinence [7]. Instrumental delivery, increasing age, increasing birth weight, length of labour are identified as risk factors [8].

Anal incontinence (AI) is defined as the involuntary loss of faeces or flatus, which adversely affects a woman's quality of life. The aim of the present study was to determine the prevalence of anal incontinence among postpartum mothers in a district of Sri Lanka and identify significant factors associated with anal incontinence.

\section{Methods}

Between 1 August and 30 September 2007 all postpartum women (at the end of 6 weeks after partus) in the Vavuniya district were asked to participate in a cross sectional study. Participants were interviewed by trained interviewers (public health midwife) at their home. The questionnaire consisted socio demographic and obstetric characteristics of participants and symptoms during the post-partum period. The diagnosis was based on the women's positive answer to the question:

"Have you ever lost control of your intestines? resulting in involuntary gas or faecal loss you did not mean to ... after childbirth?” [10].

As this study depended on participant's memory for answers there are some limitations in the study. Out of 567 postpartum mothers 540 (95.2\%) were interviewed by public health midwives for the study and 27 were not interviewed mainly because they had moved to their parents house outside the district after delivery. All the

${ }^{1}$ MD General Practitioner, Broken Hill Australia, ${ }^{2}$ Professor of Public Health, Faculty of Medicine, University of Kelaniya, Sri Lanka.

Correspondence: NR, e-mail: <Kannarohini@gmail.com>. Received 11 January 2010 and revised version accepted 11 June 2012. Competing interests: none declared. 
approached mothers agreed to participate (response rate $100 \%$ ). To increase the validity wherever appropriate records were reviewed and cross checked. The study was approved by the Ethical Review Committee of University of Kelaniya.

Data entry was carried out using a programme based on Epi data document version 3.1(Lauritsen and Braises 2004). Statistical Package for Social Scientists (SPSS Version 14.00.2008) was used for analysis and reporting. Computer data entry were done within few days which enabled to correct any errors or omissions detected in the completed questionnaire. A univariate analysis followed by bivariate analysis was carried out examining the relationship of anal incontinence with some socio demographic and obstetric variables. Individual variables were examined to see if they were associated with the anal incontinence, using chi square tests (with Yates corrector for $2 \times 2$ tables). Odd ratio was calculated wherever appropriate. Then logistic regression analysis was done to identify the independent risk factors.

\section{Results}

Maternal socio demographic and obstetric characteristics are shown in Table 1 and Table 2.

\section{Table 1. Socio demographic characteristics of women interviewed}

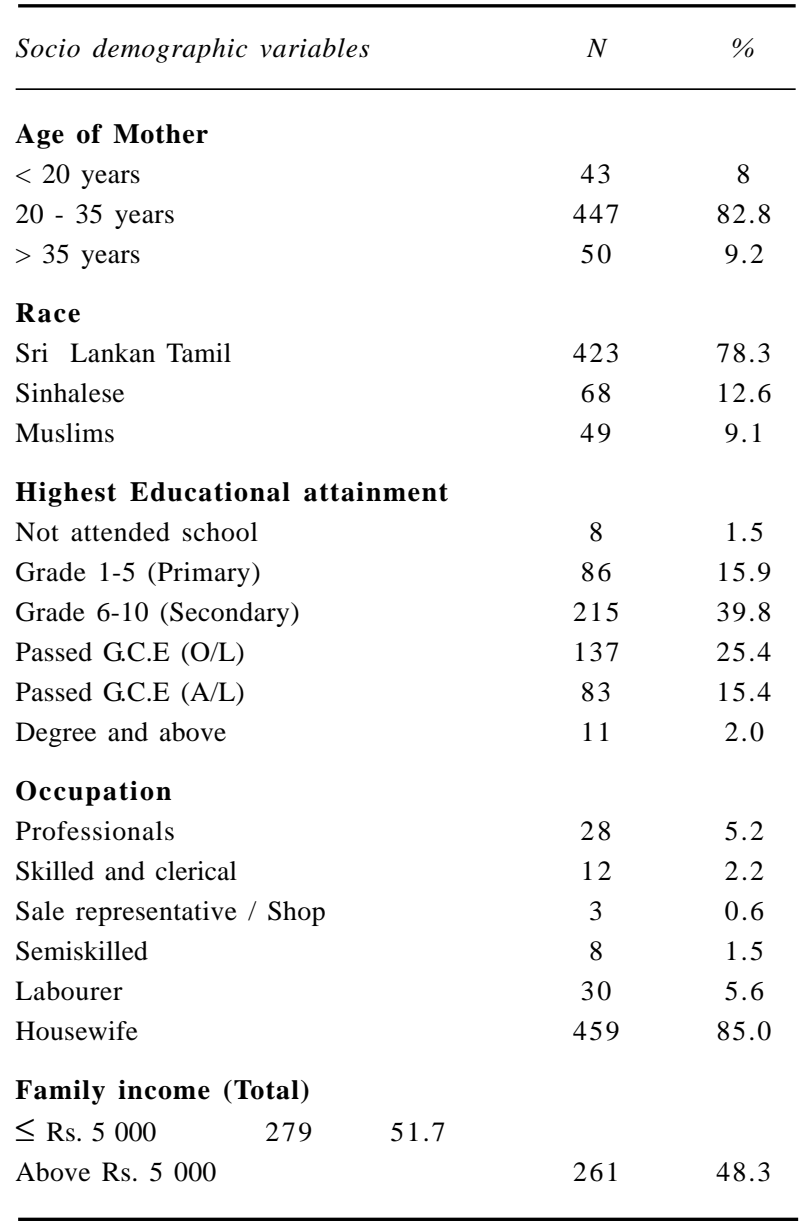

Table 2. Distribution of delivery related factors

\begin{tabular}{lcc}
\hline Obstetric Variables & $N$ & $\%$ \\
\hline Parity & & \\
Primi & 209 & 38.7 \\
Multi & 331 & 60.3 \\
Mode of delivery & & \\
Vaginal & 435 & 80.6 \\
Caessarian & 84 & 15.6 \\
Instrumental & 21 & 3.8 \\
Duration of Labour & & \\
S12 hours & 338 & 62.6 \\
More than 12 hours & 202 & 37.4 \\
Assistance of Delivery & & \\
Doctor & 314 & 58.1 \\
PHMM (Public Health Midwives) & 210 & 38.9 \\
Nurse & 4 & 0.7 \\
Others & 12 & 2.2 \\
Episiotomy performed or not & & \\
Yes & 344 & 63.7 \\
No & 196 & 36.3 \\
Birth weight of 1st baby & & \\
< 2.5 kg & & \\
2.5 - 3.5 kg & 111 & 20.6 \\
> 3.5 kg & 399 & 73.9 \\
\hline & 30 & 5.6 \\
\hline
\end{tabular}

Mean age of women interviewed was 27.7 (SD=5.5), minimum age was 16 and maximum age was 44 . Majority were Sri Lankan Tamils $78 \%(n=423), 13 \%(n=68)$ Sinhalese and remaining $9 \%(n=49)$ Moors. Fourty three (8\%) mothers were teenagers and $9 \%$ of were above the 35 years. $38.7 \%$ of study population were primi mothers and among $61.3 \%$ of multi mothers $12 \%$ were having pervious child within age of two. Around eighty one percent of women in the study delivered vaginally, $15.6 \%$ delivered by caesarian section and remaining $3.8 \%$ by instruments.

Out of 540 postpartum mothers interviewed 89 mothers (16.5\%, CI - 13.4 - 19.6) reported anal incontinence. The majority of the women who experienced anal incontinence perceived the symptom as moderate in severity. Even though 89 mothers reported anal incontinence during postpartum period only 35 mothers (39.3\%) consulted a health worker for the above morbidity. In the bivariate analysis the following factors were significantly associated with anal incontinence: parity (primi), mothers who had episiotomy (episiotomy status), duration of labour $>12 \mathrm{hrs}$, mode of delivery (vaginal), maternal age (teenage) and total family income (Table 3). Among the teenage mothers 23.3\% reported anal incontinence (Table 3). But with increasing age this decreased $(p=0.009)$. 
Table 3. Selected factors in women with anal incontinence

\begin{tabular}{|c|c|c|c|c|}
\hline \multirow[t]{2}{*}{ Characteristic } & \multicolumn{3}{|c|}{ Status of anal incontinence } & \multirow{2}{*}{$\begin{array}{c}\text { Level of significance and/ } \\
\text { ratio or odds }\end{array}$} \\
\hline & Presente No (\%) & Absente No (\%) & Total No & \\
\hline \multicolumn{5}{|l|}{ Age } \\
\hline$<20$ years & $10(23.3)$ & $33(76.7)$ & 43 & \\
\hline $20-35$ years & $78(17.4)$ & $369(72.6)$ & 447 & Chi-squares 9.356, $p=0.0009$ \\
\hline$>35$ years & $1(2)$ & 49 (98) & 50 & \\
\hline \multicolumn{5}{|l|}{ Parity } \\
\hline Primi & $61(29.2)$ & $148(70.8)$ & 209 & Chi square $39.98, p<0.001$ \\
\hline Multi & $28(8.5)$ & $303(91.5)$ & 331 & \\
\hline \multicolumn{5}{|l|}{ Family Income } \\
\hline$<5000 \mathrm{Rs}$ & $34(12.2)$ & $845(87.8)$ & 279 & Chi-squares -7.7, $p<0.01$ \\
\hline$>5000 \mathrm{Rs}$ & $55(21.1)$ & 206 (78.9) & 261 & \\
\hline \multicolumn{5}{|l|}{ Birth weight of baby } \\
\hline$<2.5 \mathrm{Kg}$ & $20(18.0)$ & $91(82.0)$ & 111 & \\
\hline $2.5-3.5 \mathrm{Kg}$ & $67(16.8)$ & $332(83.2)$ & 399 & Chi square - 2.318, $p=0.314$ \\
\hline$>3.5 \mathrm{Kg}$ & $2(6.7)$ & $28(93.3)$ & 30 & \\
\hline \multicolumn{5}{|c|}{ Episiotomy performed or not } \\
\hline Yes & $80(23.2)$ & $264(76.8)$ & 344 & $\begin{array}{l}\text { Chi square } 31.597, p<0.001 \text {, } \\
\text { Adjusted odd ratio } 3.4(\mathbf{9 5 \%} \text { CI : } \\
\mathbf{1 . 2 8 - 8 . 9 )}\end{array}$ \\
\hline No & $9(4.6)$ & $187(95.4)$ & 196 & \\
\hline \multicolumn{5}{|l|}{ Duration of Labour } \\
\hline Less than 12 hrs and equal & $45(13.4)$ & $293(86.6)$ & 336 & Chi square $6.587, p=0.001$ \\
\hline$>12$ hours & $44(21.8)$ & $158(78.2)$ & 202 & \\
\hline \multicolumn{5}{|l|}{ Mode of Delivery } \\
\hline Normal vaginal & $83(19.1)$ & 352 (80.9) & 435 & \\
\hline Instrumental & $2(9.5)$ & $19(90.5)$ & 21 & Chi square - 11.26, $\quad p=0.004$ \\
\hline Caesarian & $4(4.8)$ & $80(95.2)$ & 84 & \\
\hline
\end{tabular}

Out of 209 primi mothers 61 (29.1\%) were reported anal incontinence while out of 331 multi parity mothers only $8.4 \%$ reported anal incontinence $(p<0.001)$ (Table 3$)$. Birth weight was not significantly associated with anal incontinence even though it was shown as an associated factor in some studies [11]. Reported anal incontinence percentage is high among the group of mothers with total family income $>=$ Rs.5000 $(p<0.01)$ (Table 3). Out of 279 mothers among the less than Rs. 5000 income group 12.2\% reported anal incontinence but $21.1 \%$ mothers reported AI among the greater than Rs. 5000 income group.

Among 540 postpartum mothers 435 mothers (80.6\%) delivered vaginally. Among the mothers who delivered vaginally $19.1 \%$ of mothers reported anal incontinence but among mothers who delivered by caesarian section only $4.8 \%$ reported anal incontinence $(p=0.004)$. (Table 3).

Among 344 mothers who had episiotomy during delivery, 23.2\% reported anal incontinence. But among 196 mothers who didn't have an episiotomy during delivery only $4.6 \%$ reported anal incontinence (Table3). But the multiple logistic regression analysis revealed only having an episiotomy during delivery as an independent risk factor (adjusted odd ratio: 3.4 (95\% CI: 1.28 - 8.9). So having an episiotomy during labour increase the risk of developing AI during postpartum period by 3.4 times. 


\section{Discussion}

The present study demonstrates that anal incontinence is common among post partum mothers. Most of the mothers who reported morbidity also perceived that morbidity was not severe. In the present study we inquired about mild symptoms specifically which may explain the relatively high frequency of incontinence. Several women do not mention mild symptoms unless specifically asked for them. This was supported by the findings that only $39.3 \%$ of mothers who reported anal incontinence consulted health workers.

Anal incontinence does not constitute a severe problem for the majority of affected women. However obstetricians and midwives should ask specifically about anal incontinence at the routine postnatal examination. Women with mild symptoms can be encouraged to continue pelvic floor exercises under the guidance of physiotherapists. An association between the duration of labour and disturbances in the innervation of the anal sphincters is described [10]. Our study also demonstrated the association between labour duration and AI but multiple regression analysis failed to demonstrate this as an independent risk factor.

Frequent use of episiotomy in the community was observed in our study. Out of 540 mothers 344 mothers (63.7\%) had episiotomy during delivery. Previous reports describe episiotomy as a risk factor for sphincter tears [12]. Our study also demonstrated a strong association between episiotomy and development of anal incontinence. An association between fetal weight and sphincter tear has reported previously but was not found in our study [7]. One possible reason may be the frequent episiotomy in our study population (63.7\%).

A study has shown that increasing maternal age as a risk factor for developing anal incontinence after delivery [13]. But our study demonstrated an opposite finding to this. The possible reason again may be the high use of episiotomy especially in younger mothers and primi mothers. In our study also demonstrated that vaginal mode delivery associated with development of anal incontinence. But caesarian section was not entirely protective as $4.8 \%$ of mothers who delivered by caesarian section also developed anal incontinence.

In conclusion, this study shows that anal incontinence is a common symptom among postpartum mothers, but most perceived it as not severe. Most mothers with anal incontinence had not sought help from a health worker. The most important independent risk factor for development of anal incontinence was having an episiotomy.

\section{References}

1. Leigh RJ, Turnberg LA. Faecal incontinence: the unvoiced symptom. Lancet 1982; 319: 1349-51.

2. Nelson R, Norton N, Cautley E, Furner S. Communitybased prevalence of anal incontinence. Journal of the American Medical Association 1995; 274: 559-61.

3. Bharucha AE, Zinsmeister AR, Locke GR, et al. Prevalence and burden of feacal incontinence: a population-based study in women. Gastroenterology 2005; 129: 42-9.

4. Sultan AH, Kamm MA, Hudson CN, Thomas JM, Bartram CI. Anal-sphincter disruption during vaginal delivery. New England Journal of Medicine 1993; 329: 1905-11.

5. Fornell EK, Berg G, Hallbook O, Matthiesen LS, Sjodahl R. Clinical consequences of anal sphincter rupture during vaginal delivery. Journal of American College of Surgeons 1996; 183: 553-8.

6. Legino LJ, Woods MP, Rayburn WF, McGoogan LS. Third and fourth degree perineal tears. 50 years' experience at a university hospital. Journal of Reproductive Medicine 1988; 33: 423-6.

7. Sultan AH, Kamm MA, Hudson CN, Bartman CI. Third degree obstetric anal sphincter tears: risk factors and outcome of primary repair. British Medical Journal 1994; 308: 887-91.

8. Williams A, Herron-Marx S, Knibb R. The prevalence of enduring postnatal perineal morbidity and its relationship to type of birth and birth risk factors. Journal of Clinical Nurse 2007; 16: 549-61.

9. Snooks SJ, Setchell M, Swash M, Hentry HM. Injury to innervations of pelvic floor. Sphincter musculature in child birth. Lancet 1984; 2: 546-50.

10. Vaizey CJ, Carapeti E, Cahill JA, Kamm MA. Prospective comparison of feacal incontinence grading systems. Gut 1999; 44: 77-80.

11. Hatem M, Pasquier JC, Fraser W, Lepire E. Factors associated with postpartum urinary/anal incontinence in primiparous women in Quebec. Journal of Obstetrics and Gynaecology Canada 2007; 29: 232-9.

12. Thacker SB, Banta HD. Benefits and risks of episiotomy: an interpretative review of the English language literature, 1860-1980. Obstetric and Gynaecology Survey 1983; 38: 322-38.

13. Zetterstron JP, Lopez A, Dolk A, et al. Anal incontinence after vaginal delivery: a perspective study in primiparous women. British Journal of Obstetrics and Gynecology 1999; 106: 324-30. 